\title{
Dinámicas socio-culturales entre los grupos guaraníes frente a la violencia del régimen de encomienda. Paraguay (siglos XVI-XVII)
}

\author{
Macarena Perusset ${ }^{1}$
}

Resumen: En este artículo nos interesa estudiar el sistema de encomienda que se implantó entre los guaraníes de la gobernación del Río de la Plata y Paraguay a partir del reparto realizado por el gobernador Martínez de Irala en 1556. Al respecto analizaremos las características de dicho sistema en la sociedad platina así como la diversidad de situaciones encontradas al interior de las encomiendas. Para ello, abordaremos el análisis de la encomienda en su fase institucional, así como el impacto que ocasionó en las comunidades locales, más allá de la disminución demográfica que significó, dentro del contexto histórico y particular del Paraguay.

Palabras clave: encomienda, guaraníes, Gobernación del Río de la Plata y Paraguay, diversidad.

\begin{abstract}
In this article we are interested in studying the encomienda system which was introduced among the Guarani indians, by governor Martínez de Irala in 1556, in the Río de la Plata and Paraguay province. In this regard we will analyze the system's characteristics in that society and the diversity of situations encountered within encomiendas. To do this, we will address the analysis of the encomienda in its institutional phase, and the impact that resulted in local communities, beyond the demographic decline that meant, within the historical context and Paraguay.
\end{abstract}

Keywords: encomienda, guaraní groups, Río de la Plata and Paraguay province, diversity.

El sistema de encomienda ha sido objeto de numerosos análisis dentro de la historiografía americana, entre los cuales debemos mencionar los trabajos de Juan C.

\footnotetext{
1 Licenciada en ciencias antropológicas. Sección etnohistoria, FFyL - UBA. E-mail: macarena.perusset@gmail.com.
} 
García Santillán (1928), Enrique de Gandía (1939) y Guillermo Feliú Cruz y Carlos Monge Alfaro (1941) quienes, guidados por el referente sobre el tema, Silvio Zavala $(1935,1994)$, centraron sus investigaciones en el aspecto jurídico y legislativo que la institución adoptó en la región rioplatense. A esos estudios siguió la obra de Elman Service (1951), que focalizó su análisis en las particularidades que adquirieron las encomiendas distribuidas en territorio paraguayo, dando cuenta de las diferencias que las separaban de las restantes encomiendas del Perú. Años más tarde las investigaciones de Rafael Velázquez (1965 y 1982) caracterizaron la institución, desde una perspectiva social y económica, dentro del contexto de la producción y transporte de yerba mate, realizado a costa del trabajo indígena obtenido a través de la encomienda. Por otro lado, José Luis Mora Mérida (1973), retomando los rasgos indicados por Service (1951) dedicó un capítulo de su obra al estudio de la encomienda paraguaya, utilizando un enfoque principalmente demográfico sobre la institución. En una línea similar, los estudios más contemporáneos de María Laura Salinas (2001 y 2003) analizan el funcionamiento y organización de las encomiendas de Asunción y Villarrica a mediados del siglo XVII. Estos trabajos que ponderan la perspectiva demográfica, resultan en la reconstrucción del panorama poblacional de los grupos indígenas sujetos al régimen en cuestión. Asimismo nos resultan de interés los estudios de esta autora (1996, 1997 y 1999) sobre la evolución de las encomiendas de las jurisdicciones de Corrientes y Santa Fe, que nos brindan un panorama regional sobre lo que ocurría en la vasta gobernación del Río de la Plata y Paraguay durante los siglos XVII y XVIII. Teniendo presentes los cambios que generó esta institución entre los pueblos guaraníes, desde una perspectiva económica, Pastore (1997) aporta un breve análisis sobre las características de las encomiendas que se dieron en el Paraguay en los siglos XVI y XVII y su relación con los ciclos económicos de la provincia; y desde una visión socio-política más amplia, los trabajos de Súsnik (1965, 1982, 1983 y 1993) recorren los aspectos más significativos de los antecedentes y del proceso de formación de las encomiendas en la nueva situación de colonización en la que se vieron envueltos los guaraníes a partir del siglo XVI, sus resistencias al sistema así como distintas estrategias de acomodamiento al mismo. 
A continuación estudiaremos la encomienda en cuanto institución así como generadora de cambios y transformaciones sobre las comunidades guaraníes dentro del contexto histórico del Río de la Plata y Paraguay del siglo XVI y XVII temprano. ${ }^{2}$

En la gobernación del Río de la Plata y Paraguay, periferia del virreinato del Perú, dos hechos contribuyeron al afianzamiento de la presencia y del control hispano: por un lado la transformación de la ciudad de Asunción de casa-fuerte temporario a establecimiento base y por otro lado, la instauración del régimen de encomiendas en 1556 por el gobernador Martínez de Irala.

En la América colonial, la encomienda fue un reconocimiento del Rey a sus súbditos, por el cual se beneficiaba a los conquistadores y primeros pobladores a través del tributo y trabajo indígena como recompensa por los servicios prestados a la Corona. En la provincia del Río de la Plata y Paraguay una vez que se lograba la pacificación de un territorio, se reducían los grupos locales y el adelantado o el gobernador repartían a los indígenas entre los pobladores ${ }^{3}$, quienes debían encargarse de sus encomendados tanto en la alimentación, vestimenta, adoctrinamiento cristiano y defensa, además de enseñarles a "vivir en policía, haciendo lo demás que están obligados los encomenderos en sus repartimientos". 4 Si bien desde la península se regulaban las normas que debían regir las encomiendas, lo cierto es que cada región de América en la que se desarrollaron le imprimió sus particularidades al sistema, hecho que no escapó al Río de la Plata. Todas

\footnotetext{
2 Abordaremos las transformaciones llevadas adelante por los grupos guaraníes dentro del marco de la literatura americanista que se ha interesado especialmente en el estudio de los procesos de contacto interétnico, donde uno de los aspectos más estudiados ha sido el relacionado con los "préstamos culturales". Al respecto véase Bernand, 1997 y 1999; Boccara y Galindo, 2000; Celestino de Almeida, 2008; Gruzinski, 2000; Mattos, 2000; Motta, 1998; Quijada, Bernand y Schneider, 2000; Villalobos et al., 1982; White, 1991; entre otros.

3 Para obtener una merced de encomienda, de acuerdo con la legislación, los aspirantes debían ser beneméritos, es decir que debían ser preferidos los descendientes de los descubridores y primeros pobladores y aquellos quienes con más fidelidad hubieran servido a la Corona. Esta reglamentación establecía además los límites en la posesión, estando vedados los repartos a los hijos de quienes hubieran sido poseedores de una encomienda en última vida (pues en teoría, el beneficio de la encomienda duraba solo dos generaciones), los miembros del gobierno colonial, los miembros del clero, mulatos, mestizos, extranjeros, así como las mujeres. 4 "Luego que se haya hecho la pacificación y sean los naturales reducidos a nuestra obediencia, el adelantado, gobernador o pacificador en quien esta facultad resida, reparta los indios entre los pobladores para que en cada uno se encargue de los que fueren de su repartimiento, y los defienda y ampare, proveyendo ministro que les enseñe la doctrina cristiana y administre los sacramentos, guardando nuestro patronazgo, y enseñe a vivir en policía, haciendo lo demás que están obligados los encomenderos en sus repartimientos". Recopilación de las Leyes de Indias. Ley 3, título 8, libro VI en Zavala, 1935 p. 276.
} 
estas normas en el contexto platino se flexibilizaron y se adecuaron a las necesidades del momento y los distintos intereses en juego. En el Paraguay y Río de la Plata, eran los gobernadores (o sus lugartenientes) quienes otorgaban las mercedes de encomiendas, pero en estas tierras el reparto no sólo alcanzó a los beneméritos sino también a los nuevos pobladores y "extranjeros", De la misma manera, era muy común que la encomienda durara más de las “dos vidas” estipuladas por la legislación, al tiempo que los encomenderos pocas veces se ocupaban de la defensa y amparo de sus encomendados. Creemos que las características que esta institución adoptó en el Paraguay no fueron solo resultado de la posición geográfica que ocupaba la provincia, sino que fueron además resultado de la cultura indígena con la que los europeos entraron tempranamente en contacto, junto al hecho de no poseer minas metalíferas u otros tesoros codiciados por los españoles. Si bien fue fundamental el rol económico que significó el reparto de encomiendas, al posibilitar distribuir mano de obra indígena entre los españoles y de esa manera poner en marcha la incipiente economía paraguaya, esta no fue su única función. Sirvió también para consolidar el dominio de los españoles en el Paraguay, al posibilitarles encomendar a naturales más alejados de Asunción y de esa manera ir abriendo camino y ganando territorios para la Corona española, que se disputaba el espacio con los portugueses del Brasil.

La encomienda tuvo además, según Solveira (1999) una función militar, al asegurar la defensa de las zonas conquistadas y una función social, pues hacía posible la convivencia "pacífica" de españoles e indios y la incorporación de estos a la vida "civilizada" (Solveira, 1999). Si bien estamos de acuerdo con esta autora al considerar que la encomienda cumplió una función social, no creemos que haya sido en el marco de posibilitar una "convivencia pacífica", teniendo presente la situación de conquista experimentada por las poblaciones locales. Consideramos que la institución cumplió un rol social en la medida en que generó un espacio que permitió y estimuló el intercambio cultural, generando la convivencia al interior de las encomiendas una integración espontánea y novedosa de las distintas

\footnotetext{
5 Colección Gaspar García Viñas. En adelante CGGV. Memoria anónima sobre el gobernador Irala. Documento 1332. Tomo 82. En este contexto el término extranjero se refiere especialmente a los portugueses que se encontraban en el Paraguay y Río de la Plata y a aquellos hombres que habían escapado del Perú luego del enfrentamiento con el ejército real por las encomiendas de indios. Por los portugueses en la región véase Perusset 2006 y por los enfrentamientos en el Perú véase Drigo, 2006.
} 
tradiciones culturales, tanto europeas como indígenas, dando origen al surgimiento de nuevas y creativas formas, prácticas y creencias donde confluyeron elementos de ambas culturas, resultando en la creación de una nueva síntesis cultural. Al mismo tiempo, creemos que esta función social posibilitó la integración e implementación de valores y elementos europeos como la tecnología del hierro, la utilización del arado y otras técnicas artesanales a la vida guaraní, todo lo cual alteró y transformó los patrones nativos de organización social, política y económica tradicionales. Como resultado de esta situación, los peninsulares destinaron todos sus esfuerzos a la explotación del trabajo indígena, base de la economía local, para sacar el máximo redituable de las labores agrícolas para intercambiarlas por otros productos con los habitantes del Brasil.

Entre los grupos que se encomendaron, se siguió como base del reparto las casas de los caciques, es decir que se repartió por familias extensas o teýy, con su correspondiente jefe principal. ${ }^{6}$ En los casos en los que las encomiendas eran numerosas se generó una nueva realidad que fue la aglomeración de diversos grupos guaraníes en un mismo "pueblo de encomienda", como pasaron a denominarse desde entonces. ${ }^{7}$ Esto implicaba que distintas aldeas indígenas o teko'a y distintas familias extensas o teýy pasaron a estar juntos, al servicio de un mismo encomendero.

\section{6: el primer reparto de indios}

Desde la llegada a tierras paraguayas, los españoles se servían del trabajo indígena, que era reclutado a través de distintos medios (rancheadas, rescates, lazos de cuñadazgo, etc.). ${ }^{8}$ Estos servicios que los guaraníes prestaban a los españoles, sin un estipendio a cambio, fueron conocidos posteriormente como encomiendas de originarios y desde la década de 1570 comenzaron a ser entregadas como mercedes a los vecinos de Asunción. ${ }^{9}$ Esta forma de servicio se mantuvo vigente aproximadamente por veinte años, y continuó

\footnotetext{
${ }^{6}$ Relación de las cosas que han pasado en la provincia del Río de la Plata desde que prendieron al gobernador Cabeza de Vaca. 1556. Colección Garay. Colección de documentos relativos a la historia de América y particularmente a la historia del Paraguay. 1899. p. 269.

${ }^{7}$ Requerimiento que el factor Pedro de Orantes hizo en el año 1553 al gobernador, que poblase pueblos y encomendase indios y pone las razones de la convivencia. En Levillier, 1915.

${ }^{8}$ Véase Avellaneda y Perusset 2006.

${ }^{9}$ Mercé de alguns ianaconas a D. Juana de Mendonça de Vila Rica o espírito Santo. Assuncão. 8-1-1597. Em Manuscritos da coleção de Angelis (MCA) I. PP.125-126.
} 
incluso, una vez realizado el reparto de encomiendas de 1556. Teniendo presente estos datos, nos preguntamos ¿qué fue lo que hizo que además de este servicio se necesitara repartir más indígenas en encomienda? Es probable que la preocupación de los hispanos por el creciente descenso demográfico de la población nativa haya influido en un intento por poner un límite a la extracción de mujeres de sus comunidades, quienes de esa manera no podían contribuir a la reproducción de la fuerza de trabajo indígena, "porque por tener los cristianos gran número de indias como tenemos, a los indios les falta y dejan de multiplicar y la tierra se pierde como se ve, por experiencia que solía estar muy poblada y ahora está por muchas partes despoblada (...)". ${ }^{10}$ Serán los oficiales reales y algunos vecinos principales de la ciudad, quienes consideraban que los tratos que los españoles daban a los naturales ocasionaban el descenso demográfico, que resultaba en la disminución de las finanzas reales y a su vez incidían en sus salarios que dependían de los impuestos locales. Serán ellos quienes insistirán al gobernador Irala para repartir encomiendas bajo el leitmotiv de "dar a los cristianos servicio y a las indios amparo" ". Sin embargo, si evaluamos que transcurrieron quince años desde el establecimiento del cabildo en la ciudad de Asunción hasta el reparto, podemos comprender que este motivo no habría sido el principal para lograr las encomiendas, debido que la disminución venía desde años anteriores y los hispanos contaban con el servicio de los originarios. Además de lo que sostienen Service y Súsnik, creemos que para 1556 confluyeron una serie de coyunturas que resultaron en el reparto de "indios de mita", como se lo denominó en el Paraguay. ${ }^{12}$

\footnotetext{
${ }^{10}$ Requerimiento del factor Pedro Dorantes para que se poblase y encomendase indios y su respuesta por el teniente de gobernador Irala. 1553. En Lafuente Machaín, 2005. Dto. P.

${ }^{11}$ Requerimiento que el factor Pedro de Orantes hizo en el año 1553 al gobernador, que poblase pueblos y encomendase indios y señala las razones de la convivencia. En Levillier, 1915.

12 Debemos aclarar en este punto que en el Río de la Plata y Paraguay se denominaba a los indígenas sujetos al régimen de encomienda como "indios de mita", entendiendo este concepto como trabajo por turnos para los españoles, a diferencia de su utilización en el Perú. Una vez hecha esta aclaración, nos preguntamos ¿porqué esperar quince años para efectuar el reparto de mitayos? A este respecto Lafuente Machaín (2005) hace suya la argumentación sostenida por el gobernador Martínez de Irala al momento en que sus contemporáneos le solicitaban que hiciera el repartimiento. Frente a esta situación el mandatario alegaba que la red de parentesco que se había establecido entre hispanos y guaraníes, como consecuencia de las entregas de mujeres indígenas por parte de sus familiares a los españoles, era muy fuerte y estrecha. Por lo tanto Irala consideraba que si encomendaba a los guaraníes parientes y amigos se lesionaría esa relación que se mantenía hasta el momento gracias a los lazos de cuñadazgo (En Lafuente Machaín, 2005). Service (1951) y Súsnik (1965) señalan otras causas para dar cuenta de los quince años transcurridos entre el establecimiento en Asunción y el repartimiento de mitayos. Ambos autores señalan que el reparto de encomiendas no fue considerado hasta 1556 debido al hecho que los españoles esperaban encontrar minas de oro y plata u otros tesoros y no tenían
} 
En primer lugar se encuentra la situación de descenso demográfico indígena, que se volvía más acuciante día a día, sumado al continuo pedido de los oficiales reales y vecinos para que se hicieran los empadronamientos y el reparto de encomiendas. Además, tras haber estado casi veinte años asentados en Asunción disfrutando del servicio laboral de los originarios, los vecinos podrían considerar la encomienda como un medio para extender su control sobre otros grupos guaraníes más alejados de la capital. Las nuevas encomiendas, a diferencia de las de originarios, extendían la influencia europea sobre los pueblos indígenas que estaban alejados de la ciudad capital, al posibilitarles controlar grupos de naturales hasta entonces al margen del dominio español, e incorporarlos a un sistema colonial de servicio regulado (Service, 1951; Súsnik, 1965). Acompañando a este fenómeno del reparto de indios que se encontraban a 150 km o más de Asunción, comenzó el proceso de colonización española en la región, al permitir y estimular la fundación de nuevas ciudades en las cuales participaban los grupos encomendados para ayudar a la consolidación de la presencia ibérica y a la defensa del territorio en las nuevas fundaciones (Súsnik, 1965). Por lo tanto, el repartimiento de 1556 consistió también en una táctica para extender, visibilizar y afianzar el control hispano sobre el territorio disputado con los portugueses del Brasil y con poblaciones indígenas hostiles.

Por otro lado, debemos considerar un dato de peso para comprender la necesidad del reparto. Este se refiere a las limitaciones que comenzaron en 1552, por las cuales la Corona prohibió, a través de distintas cédulas reales, que se continuaran realizando entradas de conquista y descubrimiento en el territorio del Río de la Plata. De la misma manera, a partir de entonces, también vedó la realización de las habituales rancheadas a las aldeas guaraníes. Estas prohibiciones fueron un duro golpe para los hispanos, quienes las consideraron como un corte a los medios que les posibilitaban incrementar la cantidad de indígenas para el trabajo, al tiempo que la proscripción de hacer entradas de conquistas cercenaba sus posibilidades de encontrar nuevas tierras con metales y otras riquezas. Todo esto, junto con los constantes lamentos de habitar en una región llena de carencias y privaciones, y junto a las necesidades en las que se encontraban los pobladores del lugar, confluyó y ayudó a poner cada vez más énfasis y empeño en solicitar el reparto de 
encomiendas de guaraníes, como se hacía "en las demás provincias del Perú" 13 Consideramos entonces que la coyuntura generada por las distintas prohibiciones que limitaban la posibilidad de acrecentar el trabajo indígena a través de las rancheadas, conquistas y entradas, junto con la pacificación de nuevos grupos guaraníes que los españoles lograron para estos años, como el caso de los itatines, generó el contexto propicio para que los vecinos peninsulares solicitaran por todos los medios el reparto de encomiendas al gobernador Irala. ${ }^{14}$ Fueron entonces diversos motivos que confluyeron para que se concretara el repartimiento en 1556; pasemos ahora a ocuparnos de las características que adquirió el mismo.

\section{Las características del reparto}

El gobernador Martínez de Irala señalaba:

yo por el bien de ellos repartí [los indios de] la tierra en trescientos veinte o más hombres para que les ayudasen a sobrellevar sus trabajos y todos los dichos indios que así se repartieron serían hasta 20.000 indios y aún no llegan. (...) y hacer el dicho repartimiento entre tantos fue por dar a los conquistadores algún alivio por estar viejos y cansados. ${ }^{15}$

El reparto hecho por el gobernador Irala en 1556 comprendió a los grupos guaraníes ubicados entre los ríos Paraná, Ypané y Monday, quienes se repartieron entre más de 300 españoles. A este respecto, los oficiales reales mencionan que Irala "ha repartido y encomendado los indios de estas provincias comarcanas a esta ciudad de la Asunción y ríos del Paraguay y Paraná. ${ }^{16}$ Esta información da cuenta que el reparto se realizó con provincias guaraníes que se encontraban a 150 kilómetros de la ciudad capital, o más, correspondientes incluso a otras parcialidades, como los guarambarenses e itatines, dejando

\footnotetext{
${ }^{13}$ CGGV. Dos Reales Cédulas para que se suspendan las conquistas y descubrimientos en las provincias del Río de la Plata. 4 de noviembre de 1552. Tomo 79. Dto. 1249; CGGV. Instrucciones para Domingo de Irala. Tomo 79. Dto. 1245.

${ }^{14}$ Lafuente Machaín, 2005. Apéndice documental. Documento S p.507.

${ }^{15}$ CGGV. Relación original y parecer de las cosas y sucesos del Río de la Plata, dirigida al marqués de Mondéjar, presidente del Consejo de Indias, por el gobernador de aquellas provincias, Domingo de Irala. Tomo 79. Dto. 1239.

${ }^{16}$ Lafuente Machaín, 2005. Apéndice documental. Documento T, p. 511.
} 
de lado a los carios de los alrededores de Asunción, que ya se encontraban cumpliendo servicios laborales a los españoles.

Desde un primer momento, la constitución de estas encomiendas fue diversa pues, si bien debían repartirse entre los beneméritos de la conquista, el gobernador "la dio a extranjeros portugueses y levantiscos y franceses y a hombres que habían venido del Perú huyendo porque habían ido contra el Rey". ${ }^{17}$ Con este reparto, el gobernador se benefició en primer lugar él mismo, sus allegados y aquellos quienes habían sido sus partidarios durante el enfrentamiento con Cabeza de Vaca, pues del total de 320.000 indios de encomienda dio "el quinto de ella para él y los dos quintos para sus yernos y oficiales reales". ${ }^{18}$ Y los dos quintos restantes, "entre 290 conquistadores, dando lo mejor a los que vinieron del Perú". ${ }^{19}$ Esta situación resultó en que el número de indígenas repartidos no fuera igual para todos los favorecidos, sino que las encomiendas que se constituyeron fueron de distinta envergadura, existiendo en algunos casos brechas muy grandes entre los encomenderos. Por ejemplo, los más beneficiados pasaron a tener más de 300 indígenas para su servicio, mientras que otros no alcanzaban a un total de $10 .{ }^{20}$ Esta situación generó desacuerdos y críticas al gobernador Irala, quien acusado de haber hecho un mal reparto ${ }^{21}$, no logró satisfacer a todos los que deseaban las encomiendas pues quedaron excluidos varios pobladores, entre ellos los primeros conquistadores, quienes se sentían con más méritos y servicios que los que efectivamente las obtuvieron. Además de no haber otorgado encomiendas a los beneméritos, tampoco benefició con el reparto a quienes habían sido

\footnotetext{
${ }^{17}$ CGGV. Memoria anónima sobre el gobernador Irala. Documento 1332. Tomo 82. Relación de los sucesos y cosas ocurridas en las provincias del Río de la Plata desde que prendieron al gobernador Cabeza de Vaca. Firmada por Diego Téllez de Escobar. CGGV. Documento 1331. Tomo 82.

${ }^{18}$ CGGV. Memorial presentado al Consejo de Indias por Juan de Salmerón donde se exponen males y desaciertos de Irala. Documento 1321. Tomo 81.

${ }^{19}$ CGGV. Memorial presentado al Consejo de Indias por Juan de Salmerón donde se exponen males y desaciertos de Irala. Documento 1321. Tomo 81.

${ }^{20}$ Diario del capitán de fragata de la Real Armada Juan Francisco Aguirre [1793-1798] 1949-1951. T. II. Primera Parte p. 125. Revista de la Biblioteca Nacional. XVII-XX. No. 45-48. Buenos Aires.

${ }^{21}$ Memoria de Juan de Salmerón de Heredia a S.M. 1556; Carta de Antonio de la Trinidad a los señores presidente y oidores del Real Consejo de Indias, 2 de Julio de 1556. Ambas en Colección Blas Garay. Colección de documentos relativos a la historia de América y particularmente a la historia del Paraguay. Asunción 1899; CGGV. Memoria anónima sobre el gobernador Irala (1542-1556) Tomo 82. Dto. 1332; CGGV. Acusaciones contra Irala. Año 1557. Tomo 82. Dto. 1331. CGGV.
} 
partidarios de Cabeza de Vaca en el conflicto generado con el gobernador, ya que "no dio casi a nadie de los que tenía por enemigos". ${ }^{22}$ (Avellaneda; Perusset, 2006).

Junto con el reparto de guaraníes el gobernador dictó una serie de ordenanzas destinadas a reglamentar el correcto funcionamiento del nuevo régimen. En estas se establecía que los naturales debían obedecer y servir solo a su encomendero, al mismo tiempo que se prohibía a los indígenas entregar sus mujeres a los europeos, anulando la reciprocidad entablada por vía de parentesco. Como resultado, muchos guaraníes dejaron de servir en las casas de los españoles donde se encontraban sus parientes. Asimismo se ponía un límite, con la constitución de los pueblos de encomienda, a la movilidad tradicional guaraní, ya que pasaban a estar agrupados de manera permanente en un único lugar y les estaba prohibido mudarse de ese establecimiento. ${ }^{23}$ Sin embargo en la práctica esta normativa no se cumplió, lo que sumado a otras situaciones generó diversos levantamientos frente al sistema de encomiendas entre 1556-1580. Al respecto, Súsnik (1965) menciona al menos cinco insurrecciones guaraníes a partir de la combinación de la encomienda con las primeras estancias y la cría de ganado, por su parte Nécker (1990) señala más de veinte levantamientos, todos resultando en la resistencia guaraní y en su huída a los montes (Súsnik, 1965; Nécker, 1990). Los distintos disturbios ocasionaron que los gobernadores dictaran, a lo largo de los años, distintas ordenanzas para reglamentar y controlar el trato dispensado a los indígenas así como para organizar y normativizar el trabajo que estos debían brindar al encomendero. Esta legislación tuvo serias dificultades para ser aplicada en la práctica, por lo que en 1611-1612 fue enviado por la Audiencia de Charcas el oidor Francisco de Alfaro, quien luego de evaluar la situación, dictó una nueva reglamentación sobre el servicio personal y el tratamiento otorgado a los naturales. Los ítems más importantes de su legislación tenían que ver con la erradicación del servicio personal, al considerarlo como trabajo esclavizante y en su reemplazo se establecía el pago del tributo en especies. ${ }^{24}$ Sin embargo, a las quejas de los encomenderos y del cabildo de

\footnotetext{
${ }^{22}$ CGGV. Carta del clérigo Antonio de Escalera al emperador Carlos V, refiriendo los atropellos cometidos con el gobernador Alvar Núñez Cabeza de Vaca y abusos perpetrados con los naturales del Río de la Plata. Año de 1556. Tomo 81. Dto. 1323.

${ }^{23}$ Ordenanzas de Irala sobre repartimientos y encomiendas. 14 de mayo de 1556. En Lafuente Machaín, 2005. Dto. T. Esta reglamentación establecía una serie de obligaciones también para los encomenderos.

${ }^{24}$ Las Ordenanzas de Alfaro de 1611-1612 fueron el resultado de la labor del oidor Francisco de Alfaro, quien fue enviado a la región como consecuencia de las diversas denuncias por maltrato al que eran sometidos los
} 
Asunción se sumaron la oposición de los indígenas, quienes no se consideran a sí mismos como los esclavos que presentaba Alfaro:

Porque los más de los indios, en la visita que he hecho, especialmente en esta ciudad de la Asunción, dicen que no quisieran tasa. Unos, los más, porque no saben lo que es, aunque se les ha procurado dar a entender. Otros, porque son pobres. Otros porque dicen que ellos sirven cuando quieren y como quieren y les dan alguna gratificación los españoles. Otros, que vienen a ayudar a los españoles no a título de tasa y servicio, sino como a parientes. ${ }^{25}$

Los encomenderos y miembros capitulares reaccionaron contra las ordenanzas que prohibían el servicio personal aduciendo, la mayoría de ellos, la incapacidad de los indígenas para proveerse los bienes del tributo pues los consideraban holgazanes.

\section{Al interior de las encomiendas}

Si bien las encomiendas estaban conformadas por guaraníes, en su mayoría, existían al interior de las mismas naturales de otras etnias, como guaycurúes, agaces, tupís, que eran cautivos que los guaraníes se hacían luego de las entradas en las que acompañaban a los conquistadores. $^{26}$ En cada encomienda podía encontrarse más de un cacique debido al hecho de que en algunas, sin importar la cantidad de indígenas, convivía más de una única parcialidad bajo las disposiciones de un mismo encomendero. En ciertas ocasiones, en las que las encomiendas no contaran con líderes políticos que actuaran como autoridades, los españoles nombraban a algún integrante de la misma como administrador, pasando a tener los mismos beneficios que los caciques. Además a varias de estas encomiendas se les adosaron remanentes de grupos diezmados que fueron concentrados junto con grupos ya

indígenas locales. Luego de recorrer Tucumán, el Río de la Plata y Paraguay y otras regiones, se redactaron dichas ordenanzas en las cuales se intentaba limitar y reparar los abusos que los encomenderos realizaban a sus encomendados. A partir de entonces se reglamentaba que todo hombre entre dieciocho y cincuenta años debía prestar servicio a su encomendero, quedando exentos mujeres, niños y ancianos (además de los caciques y los empleados en las actividades de culto). Este trabajo solo debía alcanzar a uno de cada seis indígenas de los pueblos, durante un período de sesenta días al año y por el que cada hombre debía percibir una salario. La paga recibida debía cubrir los gastos del viaje hacia y desde donde debían cumplir las labores y solo podían ocuparse en el trabajo a hombres que no tuvieran que desplazarse más de diez leguas de distancia.

${ }^{25}$ Ordenanzas de Alfaro, en Hernández, 1913 p. 671 art. 57.

${ }^{26}$ ABNB-EC. Visita de los indios originarios de la ciudad de la Asunción del Paraguay. Hecha por el señor don Andrés Garabito de León. 
encomendados y en estos casos solían coincidir en una misma encomienda parcialidades diferentes y hasta enemistadas entre sí.

También se daban casos en los que algunos encomenderos, aduciendo las largas distancias que separaban a los indígenas de los lugares donde debían cumplir con su trabajo, fueron trasladando paulatinamente a una gran cantidad de encomendados hacia sus propiedades, lejos de los pueblos de encomienda. Por ejemplo, el cacique de la encomienda que poseía el vecino Atanasio de Sosa acusaba "que tenía ausentes en el Paraguay en casa de su encomendero de muchos años a esta parte más de veinte piezas". ${ }^{27}$ El número de guaraníes ausentes de sus pueblos de encomienda y que se encuentran "en casa de su encomendero" en Asunción, es recurrente. ${ }^{28}$ De esta manera, los indios de encomienda se convertían en originarios de hecho, al servicio de por vida para sus encomenderos, con todas las implicancia que esto conllevaba: "y el dicho cacique dijo que el general Lorenzo de Ortega tiene y ha hecho originarios en su casa y chacara dos indios casados con hijos llamados Juan y Domingo, los cuales le pertenecen por sujetos suyos". ${ }^{29}$ Incluso existían situaciones en las que los caciques mencionaron una cierta cantidad de guaraníes ausentes en distintos lugares, todos correctamente identificados por sus principales. Estos sitios generalmente no coincidían con la residencia o las haciendas de sus encomenderos, con lo cual nos podría estar indicando sobre los préstamos o alquileres que los españoles hacían entre sí de sus indios de servicio. ${ }^{30}$

Por lo tanto, lo que podemos observar es que existía un cuadro de diversidad inter e intraétnica en las encomiendas. En esta situación de diversidad cultural se producía una comunicación muy fluida al interior de las mismas, lo que resultaba en matrimonios mixtos

\footnotetext{
27 Visita del pueblo de San Pedro de Ypané (...) con más las visitas de los pueblos de Guarambaré, Atirá, Arecayá, Terecañe y Guiripariara. Visitador capitán Juan de Ibarra, por comisión del señor visitador don Andrés Garavito de León de la orden de Santiago. ABNB. EC. 1651.10. foja 24.

${ }^{28}$ Visita del pueblo de San Pedro de Ypané (...) con más las visitas de los pueblos de Guarambaré, Atirá, Arecayá, Terecañe y Guiripariara. Visitador capitán Juan de Ibarra, por comisión del señor visitador don Andrés Garavito de León de la orden de Santiago. ABNB. EC. 1651.10. foja 8. Esta es una situación que se repite, de hecho encontramos el testimonio del cacique Alonso de la encomienda de Clemente de Montenegro, que solicita se restituya a dos indios ausentes que están hace seis años en casa de su encomendero.

${ }^{29}$ Visita del pueblo de San Pedro de Ypané (...) con más las visitas de los pueblos de Guarambaré, Atirá, Arecayá, Terecañe y Guiripariara. Visitador capitán Juan de Ibarra, por comisión del señor visitador don Andrés Garavito de León de la orden de Santiago. ABNB. EC. 1651.10. foja 32.

${ }^{30}$ ANA. SNE. Padrón de indios de Yuty y Caazapá por el gobernador don Juan Diez de Andino 1671. F. 76 y siguientes. ANA. SNE. Vol. 392. No. 20. Visita hecha de los indios del pueblo de Ypané por don Felipe Rexe Corbalán, gobernador y capitán general de esta Provincia. Año de 1672. F. 6V. Y otros.
} 
entre guaraníes de distintas parcialidades, entre naturales de distintas etnias, e incluso entre indígenas y esclavos africanos. En la encomienda de Pedro Álvarez de Mendoza, por ejemplo, encontramos un guaraní casado con "una mulata esclava del sargento mayor Juan de Aguirre" ${ }^{\prime 3} ;$ y entre los guaraníes encomendados a Pedro Benítez encontramos un matrimonio conformado por un natural con "una mulata libre". 32

Como encomendados, los guaraníes cumplían distintas tareas: desde el trabajo de la tierra y cuidado de ganado en las estancias donde vigilaban además caballos y bueyes; el trabajo en cañaverales, trapiches y fraguas, donde forjaban metales; el trabajo en el beneficio de la yerba y su consiguiente transporte por tierra en carretas y vía fluvial a través de la conducción de balsas y barcas hacia Santa Fe, como acompañantes de guerra y en la defensa de la provincia. Además junto al trabajo que debían prestar a través de la encomienda, se solapaban los trabajos bajo la forma de "mandamientos" que tocaban a los guaraníes cada vez que el gobierno colonial lo solicitaba, en general para la seguridad de la región y para la realización de distintas obras públicas. ${ }^{33}$ Asimismo debían prestar trabajos para su comunidad y en sus propias chacras, al tiempo que tenían la posibilidad de alquilarse para otros españoles.

Si bien a partir de las ordenanzas de Alfaro de 1612 el servicio personal se veía limitado a dos meses al año, lo cierto es que muchas veces los encomenderos retenían por mayor tiempo a los indígenas en los trabajos. Los guaraníes de la encomienda del capitán Miguel de Luque dicen "que cuando van a pagar la mita que debe ser de dos meses, el dicho capitán Miguel de Luque les retiene más tiempo en que reciben molestias y agravios". ${ }^{34}$ Frente a la necesidad de los españoles del trabajo indígena, estos solicitaban a

\footnotetext{
${ }^{31}$ ANA. Sección Nueva Encuadernación. Volumen 27. Año 1693. Visita original ...

${ }^{32}$ ANA. Sección Nueva Encuadernación. Volumen 27. Año 1693. Visita original ...

${ }^{33}$ En 1686 el Cabildo de Villa Rica solicitaba indígenas para reedificar la iglesia local. ANA. SH. Vol. 36 no. 8.1. Año 1686. El cabildo de Villa Rica hace petición de auxilio de indios para reedificación de la iglesia. Padrón de indios.

${ }^{34}$ Visita del pueblo de San Pedro de Ypané (...) con más las visitas de los pueblos de Guarambaré, Atirá, Arecayá, Terecañe y Guiripariara. Visitador capitán Juan de Ibarra, por comisión del señor visitador don Andrés Garavito de León de la orden de Santiago. ABNB. EC. 1651.10. foja 2, 12 y 13. En la documentación general el término mita aparece aludiendo al servicio personal de los dos meses regulados por el oidor Alfaro: "Gaspar ausente pagando mita a su encomendero" (ANA. SNE. Vol. 392. No. 20. Visita hecha de los indios del pueblo de Ypané por don Felipe Rexe Corbalán, gobernador y capitán general de esta Provincia. Año de 1672 F.5 y siguientes). No obstante también aparece refiriéndose al trabajo realizado temporalmente en beneficio de otro particular.
} 
sus caciques una cierta cantidad de hombres para el trabajo ${ }^{35}$, los que eran generalmente utilizados para el beneficio de la yerba.

Lo que las ordenanzas de Alfaro permitieron, fue la posibilidad de emplearse en el trabajo a cambio de una paga en los restantes meses del año que no debían el servicio personal a su encomendero. A este respecto son numerosas las quejas que los guaraníes presentan sobre la falta de pago de estos españoles luego de haber trabajado para ellos. Además, en aquellos casos en los que sus encomenderos no les retribuían la paga correspondiente, el alquilarse a otros vecinos les permitía contar con ciertos bienes, como un encomendado de Pedro Gamarra y Mendoza, alcalde, que denunciaba a su amo por no haberle pagado por el cumplimiento de sus servicios, "y que algunas semanas se suele alquilar con que comprar lo que trae puesto que es bien ruin". ${ }^{36}$

Con respecto al trabajo femenino, si bien en teoría, las mujeres se encontraban exentas de la encomienda, eran compelidas a hilar una cierta cantidad de algodón a la semana, de lo contrario eran castigadas. Funcionaba así: Las indias de la encomienda de Antonio González Freire señalan "que lo que más ellas [las indias] buscan es hilando de noche para si, y la mujer del dicho su encomendero les da a hilar por tarea y que si no la dan cumplida a la tarde, les suele dar tres azotes". 37 También las mujeres guaraníes de la encomienda del maestre de campo Juan de Avalos y Mendoza "que también servían de lavar y cocinar e hilar aunque acuden a lo que les manda las obliga a que cumplan la tarea del hilado por peso que es una onza cada día y que por acabarla cumplidamente y cabal trabajan de noche". ${ }^{38}$ Además del papel de las mujeres en el cuidado de los niños, en el trabajo doméstico y el cultivo para la unidad doméstica, el trabajo propio de las mujeres consistía en "hilar, coger maíz, frijoles y algodón y ahusar el trigo"39 para la comunidad y su encomendero.

\footnotetext{
35 ANA. SCyJ. Vol 1603. No. 2. Año 1603. Querella criminal del capital Dure, protector de los naturales, contra Baltazar Carabajal sobre maltrato a los indios de su encomienda con la falta que no pareció y se supone muerto por el dicho.

${ }^{36}$ ABNB-EC. 1651.29. Visita de los indios originarios de la ciudad de la Asunción del Paraguay. Hecha por el señor don Andrés Garabito de León.

37 ABNB-EC. 1651.29. Visita de los indios originarios de la ciudad de la Asunción del Paraguay. Hecha por el señor don Andrés Garabito de León., fjs. 1-6.

${ }^{38}$ Visita de Garabito de León... ABNB-EC.1651.29 fjs. 23-28.

${ }^{39}$ Visita de Garabito de León... ABNB-EC.1651.29 fjs. 1-6.
} 
Esta situación de explotación de los guaraníes en tareas no reguladas como por ejemplo el hilado y por más tiempo del estipulado, ocasionó en definitiva la fuga de sus comunidades hacia lugares en los que encontraran cierto alivio a las presiones que debían enfrentar. De esta manera, muchas encomiendas visitadas evidenciaban un número de ausentes importante en relación a la demografía interna de las mismas, encontrando algunos casos en los que el número de presentes se asemejaba al de los huidos. ${ }^{40}$ Por ejemplo encontramos el caso de una encomienda en la que todos los guaraníes en edad de cumplir con la encomienda estaban ausentes, por lo cual se hallaba compuesta sólo por indias mujeres. ${ }^{41}$ Los hombres aparecen como ausentes "en la Asunción”, como "huidos de muchos años", tanto en la ciudad capital, en Corrientes como en las provincias de abajo e incluso en las "doctrinas que están a cargo de los padres de la Compañía". ${ }^{2}$ También encontramos referencia a una encomienda que sólo quedó compuesta por dos indias "viudas y viejas", que por tener tal condición fueron puestas en libertad con la posibilidad de volver a su natural origen. ${ }^{43}$

\section{¿Cómo trataban los encomenderos a los naturales?}

Las numerosas normativas emanadas tanto desde España, Perú o Asunción para intentar poner fin a los maltratos y abusos que los encomenderos cometían hacia sus

\footnotetext{
40 Esta situación se veía incrementada además por la presencia de los pobleros, mayordomos o administradores, encargados de la administración económica de las encomiendas.

${ }^{41}$ Con respecto a los ausentes, como mencionan algunos encomenderos en repetidas ocasiones, gran cantidad de sus encomendados que cumplen el trabajo como marineros o arrieros se quedan en las provincias de abajo, aprovechando los viajes de transporte de productos. Si cruzamos los datos que las visitas realizadas en Corrientes y Santa Fe arrojan podemos observar como estas ciudades son un polo de atracción para los indígenas del Paraguay que se movilizan y se instalan en estos lugares, desapareciendo de los padrones del Paraguay y engrosando la masa de indígenas de estos lugares, ya con un status distinto al que poseían (Garavaglia, 1983; Salinas, 2008).

${ }^{42}$ Archivo Nacional de Asunción (ANA) Sección Historia. 1671. Padrón de indios de Yuty y Caazapá por el gobernador don Juan Diez de Andino. 1671. ANA. Sección Nueva Encuadernación. Volumen 27. Año 1693. Visita original a las encomiendas de indios de Villa Rica del Espíritu Santo, hecha por el señor don Sebastián Félix de Mendiola, gobernador y capitán general de esta provincia del Paraguay en virtud de real comisión de su majestad cometiendo la visita que hizo don Felipe Rege Corvalán siendo gobernador de esta provincia. 1693.

${ }^{43}$ ANA. NE. VOL 27 AÑO 1693. Visita original a las encomiendas de indios de Villa Rica del Espíritu Santo... La diferencia entre la libertad de estas últimas con respecto a las primeras estaría dada en la edad, pues al ser indias viejas es probable que no pudieran ser aprovechadas por su encomendero para ponerlas a trabajar en servicio doméstico y en el hilado de paños, cosa que sí podría hacer con la otra encomienda de indias mujeres, en teoría más jóvenes que estas últimas, además de tener en cuenta que debía asistir en las enfermedades y dolencias de las mujeres mayores.
} 
encomendados evidencian una situación de violencia y perjuicio cotidiano a la que eran expuestos algunos grupos de indígenas. En este sentido, a raíz de las noticias que llegaban a la península sobre que se iban "acabando los indios naturales por los malos tratamientos que sus encomenderos les hacen y que habiendo disminuido tanto los dichos indios, en algunas partes faltan más del tercio; y son tratados como esclavos, se los venden y compran entre encomenderos" "44, el monarca amenazó en 1582 a los encomenderos con el "castigo de Dios, de seguir las prácticas inhumanas en la persona de los indios". ${ }^{45}$ Las injusticias que denunciaban algunos vecinos e incluso los mismos guaraníes estaban relacionadas con el tiempo de trabajo, ya que los obligaban a trabajar más de lo estipulado. Es frecuente la queja que realizan los indígenas en este sentido, por ejemplo la encomienda del capitán Lázaro Vallejos, conformada por dos parcialidades guaraníes que sumaban un total de diez naturales, los que solicitaban "que se mandase a su amo y encomendero a que no les agravase en el trabajo, de modo que aún en las fiestas les hacía trabajar y el sustento que les daba era muy limitado". ${ }^{46}$ Los indios de la encomienda del capitán Francisco Arce

dicen que el encomendero después de cumplidos sus [servicios] les detiene mucho más tiempo y este no les paga y los trabajos son excesivos (...) y los maltrata con porrazos que les da con un palo, y el sustento que les da es muy limitado y que por los malos tratamientos los dos indios ausentes de esta parcialidad se huyeron a la provincia del Tucumán y así piden que les remedie y alivien de este trabajo. ${ }^{47}$

Existían en el Paraguay colonial grandes encomenderos, propietarios de una o más encomiendas con una cantidad considerable de indígenas que trabajaran en sus tierras. Pero también existían aquellos españoles o criollos que contaban con una encomienda con escaso número de indios, que poco o nada podían trabajar en sus tierras y era este quien se ponía a trabajar por necesidad, a la par de sus indios encomendados. Pruebas de esta diferencia de poder económico entre los encomenderos encontramos entre las declaraciones

\footnotetext{
${ }^{44}$ ANA. SH. Vol. 1. No. 37. F 32 y ss.

45 ANA. SH. Vol. 1. No. 37. F 32 y ss.

${ }^{46}$ Visita del pueblo de San Pedro de Ypané (...) con más las visitas de los pueblos de Guarambaré, Atirá, Arecayá, Terecañe y Guiripariara. Visitador capitán Juan de Ibarra, por comisión del señor visitador don Andrés Garavito de León de la orden de Santiago. ABNB. EC. 1651.10. foja 5.

${ }^{47}$ Visita del pueblo de San Pedro de Ypané (...) con más las visitas de los pueblos de Guarambaré, Atirá, Arecayá, Terecañe y Guiripariara. Visitador capitán Juan de Ibarra, por comisión del señor visitador don Andrés Garavito de León de la orden de Santiago. ABNB. EC. 1651.10. foja 16.
} 
de los indígenas, al decir por ejemplo que todos servían por su voluntad a su encomendero "porque lo ven pobre y con hijos". ${ }^{48}$ De la misma manera encontramos un grupo de indios oficiales de herrería a quienes su encomendera no les pedía trabajo alguno, pero de todas maneras ellos con lo que ganaban la ayudaban económicamente "con lo que pueden" y además, para que no le faltara el servicio doméstico que podría precisar los mismos indios le dejaron a dos de sus hijos mayores para que le sirvieran "y aunque algunas ocasiones la dicha su encomendera les ha querido dar algún pedacillo de lienzo no lo reciben porque echan de ver su necesidad". 49

Como ya señalamos, la instauración de este régimen de trabajo sacudió a las comunidades indígenas que se rebelaron contra él (Súsnik, 1965, 1982; Nécker, 1990; Roulet, 1993; Velázque, 1965, 1982), y si bien los distintos mandatarios dictaron distintas reglamentaciones para controlar el trato a los indígenas, los alzamientos registrados contra el régimen tornan evidente que esta legislación no se cumplió. En este marco, como parte de las respuestas de los naturales en relación a las encomiendas podemos incluir su huida al Brasil. Mucho se ha escrito sobre la despoblación de esta región a causa de las bandeiras paulistas que venían en busca de mano de obra indígena para los ingenios portugueses, además de venir en busca de mano de obra para las minas de la capitanía de San Vicente (Mendonça, 1985). Es de sobra conocida la violencia ocasionada por las bandeiras entre los pueblos guaraníes y las villas de españoles, pero a pesar de ello, parte de la documentación da cuenta que los guaraníes partían de buena gana hacia el Brasil, pues "se quieren ir con sus parientes para San Pablo". 50

Con la reunión de las coronas ibéricas en 1580, fue dividido el Brasil en una repartición Norte y una repartición Sur, estando esta última en manos de Francisco de Souza. ${ }^{51}$ Este gobernador llevó adelante un plan de colonización basado en hacer incursiones al interior del territorio para buscar mano de obra indígena destinada al trabajo

\footnotetext{
${ }^{48}$ ABNB. EC 1651.29. Visita a los indios originarios a la ciudad e la Asunción del Paraguay... foja 7 y 23.

${ }^{49}$ ANB-SEC 1651.29. ABNB-EC. 1651.29. Visita de los indios originarios de la ciudad de la Asunción del Paraguay. Hecha por el señor don Andrés Garabito de León, f. 8.

${ }^{50}$ ANA SC. Vol. 5 no. 17. 6 de marzo de 1676. El licenciado José Mongelos y Garcés hace una relación minuciosa del movimiento de los portugueses y Diez de Andino que ha salido a su persecución. F. 114.

${ }^{51}$ Durante la colonización de las tierras de América del Sur se produjeron, entre Castilla y Portugal, mutuas influencias con respecto a la formación del estado brasileño, entre las que podemos señalar la creación de la Repartición Norte y la Repartición Sur del Brasil, promovida por iniciativa hispana (Hoyuela Jayo, 2007).
} 
en las minas (Ruiz González, 2002). Con este fin, y luego de que las misiones jesuitas del Guairá se establecieran y comenzaran a tomar cuerpo, Francisco de Souza y posteriormente su hijo Luis, junto con los jesuitas de San Pablo, en la capitanía de San Vicente, idearon una estrategia para atraer a los guaraníes a la ciudad paulista. Los padres jesuitas portugueses enviaron al Guairá algunos caciques tupí para persuadir a los guaraníes del Paraná a que se marcharan con ellos al Brasil. De hecho, "por orden de los dichos padres fueron despachados los dichos caciques a sacar de este pueblo todos los indios e indias que se quisiesen ir con ellos como los propios indios lo dicen". ${ }^{2}$ El plan de captación del indígena paraguayo era parte del plan para la explotación de las minas de San Pablo, y los caminos que unían la zona del Paraná con Santa Catarina eran la vía ideal que les permitía ir en la búsqueda de la mano de obra deseada.

Los cuales Capitanes (...) les darán órdenes para ir al sertão [interior] a persuadir a los dichos gentíos para que bajen, tanto con buenas palabras y blandura, como con promesas, sin hacerles fuerza ni molestia alguna, en caso que no quieran venir, para lo cual llevarán otro de cualquier otra religión o clérigo, que sepa la lengua, para así poderlos persuadir mejor. ${ }^{53}$

De este fragmento se desprende que los paulistas iban un paso adelante, pues no sólo enviaban a los religiosos que supiesen bien la lengua, sino que enviaban a los propios indígenas. Y ya que se trataba de persuadir, quién mejor que los caciques para encargarse de explicar cómo y por qué era mejor vivir en San Pablo que en Asunción o en el Guairá.

Por una carta del teniente general de gobernador y juez visitador, Antonio de Añasco, al gobernador de Buenos Aires, se deduce que tanto los colonos como los jesuitas y el gobernador de la Repartición del sur de Brasil estaban llevando a cabo una política conjunta. Así daba cuenta que el jefe de los paulistas, Pedro Vaes de Barros fue hasta Asunción con treinta y dos portugueses y muchos indios tupís y llevaba

una comisión que el gobernador de San Pablo Don Luis de Sousa hizo de don francisco de Sousa, que dios haya (...) y así por la muerte de su padre está gobernando el dicho don Luis el cual dio una comisión a los caciques como por

\footnotetext{
${ }^{52}$ A.G.I., Charcas, 112. Carta de 14-11-1611 de don Antonio de Añasco al gobernador de Buenos Aires Diego Marín Negrón sobre los excesos que cometían los portugueses de San Pablo del Brasil.

${ }^{53}$ Licencia del 30 de Julio de 1609 sobre la libertad indígena (Alvará de 30 de julho de 1609 sobre a liberdade indígena). En Thomas, 1982. Documento No.6.
} 
vuestra señoría será vista por el trasunto que envío sacado y traducido en castellano a la letra para que vuestra señoría lo vea. ${ }^{54}$

La carta de Añasco era un pedido explícito para que el gobernador del Río de la Plata solicitara al Provincial de los jesuitas que intercediera para que "los demás padres de la compañía de San Pablo que no se metan en esta jurisdicción pues hay ya reducción y doctrina de los padres". 55 Sin embargo, los paulistas estaban actuando de acuerdo con las normas de la ley de 1609 que establecía que los capitanes civiles y los religiosos debían organizar las cosas para adentrarse en el territorio y persuadir a los indígenas para que se fueran con ellos a la ciudad para trabajar en la explotación minera. ${ }^{56}$

Inmediatamente después de la entrada de los colonos y jesuitas paulistas en territorio paraguayo, se produjo una verdadera disputa entre asunceños y paulistas para mantener a los indios bajo su control. Los vecinos españoles se sentían impotentes para conseguir mantener a los guaraníes en sus tierras. Los guaraníes por su parte, se veían atraídos por las promesas que los lusitanos y los tupís les hacían, razón por la cual fueron abandonando las reducciones y los pueblos de encomienda cercanas al río Paraná para incorporarse a los aldeamentos portugueses. En 1610 los integrantes del cabildo de Ciudad Real informaban al gobernador de Buenos Aires que se habían ausentado más de tres mil indios en dirección a San Vicente ${ }^{57}$ y en 1612 Bartolomé de Torales escribía alertando al gobernador del Río de la Plata acerca de que trece caciques y más de novecientos indios abandonaron la provincia siguiendo al paulista Sebastián Preto “que los llevó con puras dádivas". 58

Las ciudades de Villa Rica, Ciudad Real y Jerez, situadas cerca de las misiones que la Compañía había fundado en la región del Guairá en la provincia del Paraguay, estaban

\footnotetext{
${ }^{54}$ AGI. Charcas 112. Carta de 14-11-1611 de don Antonio de Añasco al gobernador de Buenos Aires Diego Marín Negrón sobre los excesos que cometían los portugueses de San Pablo del Brasil.

55 AGI. Charcas, 112. Carta de 14-11-1611 de don Antonio de Añasco al gobernador de Buenos Aires Diego Marín Negrón sobre los excesos que cometían los portugueses de San Pablo del Brasil.

${ }^{56}$ Licencia del 30 de Julio de 1609 sobre la libertad indígena (Alvará de 30 de julho de 1609 sobre a liberdade indígena). En Thomas 1982, Documento No.6.

${ }^{57}$ AGI, Charcas, 112. Ciudad Real, 20-12-1612. Carta del Cabildo de Ciudad Real al gobernador de Buenos Ayres Diego Marín Negrón sobre la inquietud que los portugueses de San Pablo del Brasil causaban entre los naturales de aquella región.

58 AGI, Charcas, 112. Guairá, 19-12-1612. Carta de Bartolomé Torales al Gobernador del Río de la Plata Diego Marín Negrón sobre el alzamiento y huída de los indios de la provincia de Guayrá sonsacados por los portugueses de la villa de San Pablo.
} 
entrando en colapso, debido a la saca de guaraníes estimulada desde el Brasil, como por aquellas que involucraban la saca violenta de indios. El gobernador del Río de la Plata escribía al Rey sobre la escasez de mano de obra que sentían los encomenderos del Guairá, ya que desde

dos años a esta parte han estado los naturales encomendados a los vecinos de esta ciudad tan alterados e inquietos por la entrada de Rondon que han hecho los portugueses entre ellos y los han sonsacado y llevado más de tres mil ánimas a la villa de San Pablo en harto perjuicio de esta ciudad. ${ }^{59}$

Por supuesto estas bandeiras "pasivas" se sumarán a las ya conocidas bandeiras o malocas paulistas, que harán un extensivo uso de la violencia para extraer mano de obra y al mismo tiempo destruir los poblados que encontraban a su paso, tanto indígenas como españoles. Teniendo presente lo señalado anteriormente, queremos dar cuenta que la despoblación de los pueblos de indios del Guairá muchas veces atribuida a la violencia de las bandeiras, tenía también otra cara, que hemos denominado "bandeiras pasivas", las cuales fueron ideadas y comandadas al mismo tiempo por los funcionarios y jesuitas del Brasil. La coexistencia de estas dos modalidades en la saca de indios, junto a las situaciones mencionadas acerca de las encomiendas, nos hace reflexionar una vez más sobre la situación que vivirían los guaraníes bajo la conducción de encomenderos o religiosos hispanos, quienes al encontrar una oportunidad, abandonaron sus pueblos y se marcharon al Brasil.

\section{Innovaciones, alteraciones y transformaciones: lo que la encomienda significó}

Para los naturales sujetos al régimen encomendil, uno de los cambios más importantes tuvo que ver con la alteración en los patrones de residencia indígena. Recordemos que los grupos guaraníes prehispánicos vivían agrupados en pequeñas aldeas o teko'a, organizados en familias extensas teýy, y alternaban la ubicación de sus aldeas así como de sus terrenos de roza cada tres o cuatro años (Silva Noelli, 2004). No sólo el

\footnotetext{
${ }^{59}$ AGI, Charcas, 112. Buenos Aires, 8-01-1612, Carta del gobernador de Buenos Aires Diego Marín Negrón a Su Majestad sobre la separación de los gobiernos del Río de la Plata y Paraguay y excesos cometidos por los portugueses de San Pablo.
} 
reparto, sino también la legislación que lo acompañó introdujeron cambios en estas comunidades, pues la misma establecía que los guaraníes debían residir de manera permanente en los nuevos "pueblos de encomienda", limitando con esto las prácticas tradicionales de mudanzas de territorio. Los efectos del control español afectaron también los patrones de aglomeración indígena, pues pasaron a estar agrupados en aldeas más grandes y permanentes, con el fin de reducirlos a un control más fácil y efectivo. De esta manera, el reparto de indios provenientes de diferentes aldeas generó nuevas entidades y realidades, así como nuevas dinámicas en las relaciones entre ellos, que en el futuro constituirían la base de una nueva distribución y aglutinación en las reducciones franciscanas. ${ }^{60}$ Además, las encomiendas y las ordenanzas implicaron que los guaraníes debían obedecer y servir, a partir de entonces, únicamente a su encomendero, alterando de esa manera la organización política y económica que se había desarrollado en el Paraguay desde la llegada de los españoles, donde los guaraníes solían trabajar o servir a varios y diferentes señores, cuñados o parientes, a la vez. ${ }^{61}$

Las ansias de control y de enriquecimiento de los españoles llevaron, además, a la instalación en los pueblos de encomiendas de la figura de un administrador (también llamado poblero o mayordomo) encargado de la administración económica del mismo. ${ }^{62}$ En su afán económico estos personajes explotaban el máximo posible a los indígenas encomendados, al tiempo que cometían una serie de abusos, tanto en el orden económico como moral, lo que llevará posteriormente a legislar a favor de la desaparición de la institución del poblero. Frente a estos sujetos, los líderes indígenas anteriormente al frente de sus pueblos, vieron reducido notablemente su poder. Por lo tanto, la encomienda ocasionó además, que la organización política prehispánica fue rápidamente desplazada por la reglamentación española desde el momento en que los jefes étnicos fueron reemplazados

\footnotetext{
${ }^{60}$ Las reducciones franciscanas, también llamadas pueblos de indios, fueron el primer intento de reducir indígenas en el Paraguay, llevado a cabo a partir de 1580 por los curas franciscanos.

${ }^{61}$ Ordenanzas de Irala sobre repartimientos y encomiendas. 14 de mayo de 1556. En Lafuente Machaín 2005. Dto. T.

${ }^{62}$ Mayo (1978) en un estudio sobre los administradores de encomiendas del Tucumán colonial señala las diferencias existentes entre la función de administrador, poblero y mayordomo (Mayo 1978). Para el Paraguay no hemos encontrado tales distinciones.
} 
en la mayoría de sus funciones por los administradores o pobleros. ${ }^{63}$ No obstante estar notablemente disminuidos en sus funciones, se volvía necesario contar con una figura respetada por la comunidad indígena para organizar el funcionamiento del trabajo de los indios encomendados. Para ello era fundamental basarse en las autoridades de los pueblos guaraníes, a las que había que re estructurar habida cuenta de que las autoridades étnicas tradicionales guaraníes eran temporarias y no coercitivas. Por esta razón se instituyó en estos nuevos pueblos de encomiendas la figura del cacique y se integró la división de los guaraníes de acuerdo a las parcialidades. De esta manera cada uno de los caciques era el responsable de que sus indios cumplieran con el servicio que debían a sus encomenderos. ${ }^{64}$ Como los españoles iban a depender fundamentalmente de los principales para esto, era menester un buen trato hacia ellos, razón por la cual se los eximió, junto con sus familias, de tener que cumplir con el trabajo. ${ }^{65}$ Con este beneficio, junto con la denominación de “don” y el trato preferencial dispensado a estos líderes étnicos, los españoles creían asegurarse el trabajo de sus encomendados. En este sentido, debemos mencionar que la actitud de los líderes nativos varió mucho dependiendo del margen de posibilidades que encontraron en cada situación específica y de las respuestas que podían generar frente al avance de la sociedad colonial.

Por otra parte, la limitación en la movilidad de las aldeas guaraníes buscaba fortalecer la estabilidad de los nuevos pueblos de encomienda, a la vez que la legislación establecía que los encomenderos no tenían derechos sobre las tierras comunales de los naturales como tampoco podían intervenir en la utilización de las mismas. Sin embargo, guiados por las ansias de enriquecimiento, tanto los encomenderos como los pobleros llevaron hasta el máximo posible la capacidad laboral guaraní, a la vez que pusieron en marcha la implementación de nuevas tecnologías para reemplazar las antiguas técnicas indígenas de uso de la tierra. Frente a esta situación, no solo se debilitaba la economía guaraní por la extracción de mano de obra, sino que sufría una modificación fundamental en cuanto a la incorporación de nuevas tecnologías como las hachas de hierro que

\footnotetext{
${ }^{63}$ Será recién a partir de las ordenanzas de Hernandarias (1598 y 1603) y con las del visitador Alfaro (1611) cuando se legislará a favor de la existencia de fiscales y corregidores indígenas quienes estarán a cargo, junto con el cacique y el cabildo indígena, del pueblo de indios (Hernández, 1913; García Santillán, 1928).

${ }^{64}$ Ordenanzas de Ramírez de Velasco. Ordenanza no. 8. En García Santillán, 1928.

${ }^{65}$ Ordenanzas Hernandarias. En García Santillán, 1928.
} 
utilizaban para realizar las rozas, las ruedas para realizar hilados, así como la incorporación de aves de corral y cerdos para criar (Súsnik, 1965). Por lo tanto la incorporación de distintos elementos y técnicas europeas a la cultura guaraní generó transformaciones, que se trasladaron a la producción en la agricultura y cría de animales, hilado y trabajo artesanal que los europeos intentaron aprovechar al máximo.

Pero además, la encomienda ocasionó alteraciones profundas en los pueblos guaraníes, pues cuando un grupo de naturales debía trabajar para el encomendero, los pueblos quedaban desamparados durante ese tiempo, generalmente en ocasión de siembra y cosechas. De esta manera se debilitaba la propia economía indígena porque se veía profundamente afectada la antigua organización del trabajo por cooperación y reciprocidad, pasando a un segundo plano los intereses familiares tradicionales. Junto al descenso demográfico, esta ausencia afectaba el delicado balance del tamaño de las familias, el tamaño de la población en general, los lazos de solidaridad y cooperación en cuanto a los trabajos destinados a la subsistencia, así como las prácticas de matrimonio tradicionales. Pero probablemente los cambios más importantes que generó el sistema de encomienda sobre los grupos guaraníes hayan sido los efectos resultantes del uso de los indígenas como fuerza de trabajo, en conjunto con las demás obligaciones laborales a las que debían acudir. En un primer momento fueron utilizados en las distintas actividades agrícolas que generaban los productos destinados al intercambio con otras ciudades. En las áreas donde crecía la yerba mate, los guaraníes eran empleados de manera intensiva en el trabajo de corte y curado de la yerba, para luego emplearlos en el transporte terrestre o fluvial, hacia los distintos mercados.

Por todo lo expresado anteriormente podemos observar que la encomienda de indios sirvió para poner en marcha la incipiente economía paraguaya, así como para consolidar el dominio de los españoles en el Paraguay, al posibilitarles encomendar a naturales más alejados de Asunción y de esa manera ir abriendo camino y ganando territorios para la Corona española, que se disputaba el espacio con los portugueses del Brasil. Si bien no podemos desconocer el debilitamiento que este régimen implicó para las comunidades guaraníes, la encomienda generó un espacio para la comunicación entre dos códigos culturales disímiles, es decir que la interacción que se dio al interior de las mismas permitió que se fundieran, permearan, transformaran y crearan nuevas prácticas, usos y costumbres, 
dando como resultado prácticas mixtas en manos de distintos actores sociales. De esta manera, el abanico de posibilidades laborales (cultivo y cosecha de sembradíos, transporte de cargas por vía terrestre y fluvial, cuidado de caminos, acompañamiento de los encomenderos en viajes, entre otros) actuó como un espacio y como un vehículo de intercambio cultural, ya que permitió que en el contacto y en la convivencia con los españoles se generaran negociaciones así como prácticas, flexibles, que les permitieron desenvolverse mejor en el contexto colonial.

Por lo tanto, las encomiendas no solo generaron cambios y transformaciones en los patrones culturales indígenas, sino que además fueron el espacio en el cual se desarrolló un intercambio constante y flexible de hábitos y costumbres diferentes que se evidenció en la elasticidad de prácticas y creencias de los sujetos involucrados en la interrelación.

\section{Archivos consultados}

Archivo y Biblioteca Nacionales de Bolivia (ABNB).

Archivo General de Indias (AGI).

Archivo Nacional de Asunción (ANA).

\section{Bibliografía}

AGUIRRE, Juan F. Diario del capitán de fragata de la Real Armada Juan Francisco Aguirre [1793-1798]. Revista de la Biblioteca Nacional. Buenos Aires, XVII-XX, n. 45-48, 19491951.

AVELlANEDA, M.; PERUSSET, M. Irala, el gran estratega del Río de la Plata. Anuario de la Academia Paraguaya de la Historia. Asunción, v. XLVI, p. 319-363, $2006 .$. BERNAND, Carmen. Los caciques de Huánuco 1548-1564: el valor de las cosas. In: ARES QUEIJA; GRUZINSKI (Coord.) Entre dos mundos. Fronteras culturales y agentes mediadores. Sevilla: Escuela de estudios hispanoamericanos de Sevilla, 1997. p. 61-91. Los híbridos en Hispanoamérica. Un enfoque antropológico de un proceso histórico. In: BOCCARA; GALINDO (Ed.). Lógica mestiza en América. Temuco: Instituto de Estudios Indígenas; Universidad de la Frontera, 1999. 
BOCCARA, G.; GALINDO, S. (Ed.). Lógica mestiza en América. Temuco: Instituto de Estudios Indígenas; Universidad de la Frontera, 2000.

CELESTINO DE ALMEIDA, M. Regina. Índios e mestiços no Rio de Janeiro: significados plurais e cambiantes (séculos XVIII-XIX). Memoria Americana. Buenos Aires: Facultad de Filosofía y Letras; UBA, vol. 16 (1,2), p. 19-40, 2008.

COLECCIÓN BLAS GARAY. Colección de documentos relativos a la historia de América y particularmente a la historia del Paraguay. Tomo I, Asunción, 1899.

COLECCIÓN GASPAR GARCÍA VIÑAS (CGGV). Buenos Aires: Biblioteca Nacional de Buenos Aires, 1920.

DRIGO, Ana Laura. La gran rebelión de Gonzalo Pizarro: liderazgo y legitimidad (Perú siglo XVI). Buenos Aires: Editorial Dunken, 2006.

FELIÚ CRUZ, G.; MONGE ALFARO, C. Las encomiendas según tasas y ordenanzas.

Buenos Aires: Instituto de Investigaciones Históricas; UBA, 1941.

GANDÍA, Enrique de. Francisco de Alfaro y la condición social de los indios. Buenos Aires: El Ateneo, 1939.

GARAVAGLIA, Juan Carlos. Mercado interno y economía colonial. Ciudad de México:

Editorial Grijalbo, 1983.

GARCÍA SANTILLÁN, Juan C. Legislación sobre indios en el Río de la Plata en el siglo XVI. Madrid: Biblioteca de Historia Hispano Americana, 1928.

GRUZINSKI, Serge. El pensamiento mestizo. Barcelona: Editorial Paidós, 2000. HERNÁNDEZ, Pablo. Organización social de las doctrinas guaraníes de la Compañía de Jesús. Barcelona: Ed. Gustavo Gili. Barcelona, 1913. (Ordenanzas de Alfaro, vol II, appendix 56: 661-677).

LAFUENTE MACHAÍN, R. (1939). El gobernador Domingo Martínez de Irala. Asunción: Academia Paraguaya de la Historia, 2006.

HOYUELA JAYO, Antonio. Brasil, una costrucción hispánica. El papel de la Unión de las Coronas en la definición de un urbanismo original ibérico. In: SIMPÓSIO LUSO-

BRASILEIRO DE CARTOGRAFIA HISTÓRICA, 1., 2007. p. 1-29.

LEVILLIER, Roberto. Correspondencia de los oficiales reales de hacienda del Río de la Plata con los reyes de España. T. I: 1540-1606, Madrid, 1915. 
MANUSCRITOS COLECCIÓN DE ANGELIS (MCA). Jesuitas e Bandeirantes no Itatim (1596-1760). Introducción, notas y glosario por Jaime Cortesão. Rio de Janeiro: Biblioteca Nacional; Divisão de Obras Raras e Publicações, v. I, II.

MATIENZO CASTILLO, Javier. La encomienda y las reducciones jesuíticas de América meridional. Temas Americanistas. Sevilla: Departamento de Historia de América; Universidad de Sevilla, n. 21, p. 66-84, jul.-dic. 2008.

MATTOS, Hebe. Escravidão e cidadania no Brasil Monárquico. Rio de Janeiro: Zahar, 2000.

MENDONÇA, Marcos Carneiro. Rios Guaporé e Paraguai. Primeiras Fronteiras

Definitivas do Brasil. Rio de Janeiro, 1985. (Xérox).

MORA MÉRIDA, José Luis. Historia social del Paraguay, 1600-1650. Sevilla: Escuela de estudios hispano americanos, 1973.

MOTTA, Márcia M. Terra, nação e tradições Inventadas (uma outra abordagem sobre a lei). In: MOTTA, M.; MENDONÇA, S. (Comp.) Nação e poder: as dimensões da história. Niterói: Eduff, 1998. p. 81-92.

NÉCKER, Louis.(1979). Indios guaraníes y chamanes franciscanos. Las primeras reducciones del Paraguay (1580-1800). Biblioteca paraguaya de antropología. Asunción: Centro de estudios antropológicos; Universidad Católica, v. 17, 1990.

PASTORE, Carlos. La lucha por la tierra en Paraguay. Montevideo: Antequera, 1972. PERUSSET, Macarena. Contrabando y sociedad en el Río de la Plata Colonial. Buenos Aires: Editorial Dunken, 2006.

QUIJADA, Mónica; BERNAND, Carmen; SCHNEIDER, Arnd. Homogeneidad y nación. Con un estudio de caso: Argentina, siglos XIX y XX. Madrid: Consejo Superior de Investigaciones Científicas; Centro de Humanidades, 2000.

SALINAS, María Laura. 2008. Encomienda, trabajo y servidumbre indígena en Corrientes. Siglos XVII-XVIII. Tesis (V Maestría en Historia de América) — Universidad Internacional de Andalucía, 2008.

. Pueblos de indios, reducciones franciscanas y encomiendas en Paraguay a mediados del siglo XVII. In: Anuario 2003. Archivo y Biblioteca Nacionales de Bolivia, Sucre, p. 479-508,dic. 2003 
. La población guaraní en las encomiendas de Paraguay a mediados del siglo XVII según la visita del oidor Garabito de Léon. In: ENCUENTRO DE GEOHISTORIA REGIONAL, 21., 2001, Actas... Formosa: Gualamba, agosto 2001. p. 315-331. . Indios de encomienda en Corrientes y Santa Fe. La visita del oidor Garabito de León (1650-1653). Cuadernos de Geohistoria Regional. Resistencia: Instituto de Investigaciones Neohistóricas; CONICET, n. 36, 1999. . Las encomiendas en los pueblos de Santiago Sánchez y Santa Lucía a mediados del siglo XVII. In: ENCUENTRO DE GEOHISTORIA REGIONAL, 17., Formosa: Universidad Nacional de Formosa, 1997. Evolución de las encomiendas indígenas en el Paraguay. 1754-1780. In: ENCUENTRO DE GEOHISTORIA REGIONAL, 16., Resistencia: Instituto de investigaciones Geohistóricas, CONICET, 1996. p. 511-523.

SERVICE, Elman. The Encomienda in Paraguay. Hispanic American Historical Review. Duke University Press, n. 31, p. 230-252, 1951. . Tobati: Paraguayan Town. Chicago: University of Chicago Press, 1954.

SILVA NOELLI, Francisco. La distribución geográfica de las evidencias arqueológicas guaraní. Revista de Indias. Consejo superior de investigaciones científicas, v. LXIV, n. 230, 2004.

SOLVEIRA, Beatriz. Encomiendas de indios y distribución de la tierra. In: Nueva historia de la nación argentina. Buenos Aires: Planeta, 1999. p. 477-507.

SÚSNIK, Branislava. El indio colonial del Paraguay. El guaraní colonial I. Asunción: Museo Etnográfico Andrés Barbero, 1965. . El rol de los indígenas en la formación y vivencia del Paraguay. Asunción: Instituto Paraguayo de Estudios Nacionales, v. I, 1982. . Asunción: Instituto Paraguayo de Estudios Nacionales, v. II, 1983. Una visión socio-antropológica del Paraguay. Asunción: Museo Etnográfico Andrés Barbero, XVI - 1/2 XVII, 1993.

THOMAS, Georg. Política indigenista dos portugueses no Brasil, 1500-1640. São Paulo: Loyola, 1982.

VELÁZQUEZ, Rafael. Caracteres de la encomienda paraguaya en los siglos XVII y XVIII. In: Historia paraguaya. Asunción, v. XIX, 1982. p. 113-163. 
. La rebelión de los indios de Arecaya en 1660: reacción indígena contra los excesos de la encomienda en el Paraguay. Asunción: Centro Paraguayo de Estudios sociológicos, 1965.

VILLALOBOS, Sergio. Tres siglos y medio de vida fronteriza. In: VILLALOBOS, S. et al.. Relaciones fronterizas en la Araucanía. Santiago: Ediciones Universidad Católica de Chile, 1982. p. 9-64.

ZAVALA, Silvio. La encomienda indiana. Madrid: Junta para Ampliación de Estudios e Investigaciones Científicas; Centro de Estudios Históricos; Sección Hispanoamericana II, 1935. 